\title{
A Case Study on the Walking Speed of Pedestrian at the Bus Terminal Area
}

\author{
Mohd Firdaus Mohamad Ali ${ }^{1}$, Muhamad Salleh Abustan ${ }^{1, *}$, Siti Hidayah Abu Talib ${ }^{1}$, \\ Ismail Abustan ${ }^{2}$, Noorhazlinda Abd Rahman ${ }^{2}$, and Hitoshi Gotoh ${ }^{3}$ \\ ${ }^{1}$ Faculty of Civil and Environmental Engineering, Universiti Tun Hussein Onn Malaysia, 86400 Parit \\ Raja, Batu Pahat, Johor, Malaysia \\ ${ }^{2}$ School of Civil Engineering, Universiti Sains Malaysia, 14300 Nibong Tebal, Penang, Malaysia \\ ${ }^{3}$ Department of Civil and Earth Engineering, Kyoto University, Japan
}

\begin{abstract}
Walking speed is one of the factors in understanding the pedestrian walking behaviours. Every pedestrian has different level of walking speed that are regulated by some factors such as gender and age. This study was conducted at a bus terminal area with two objectives in which the first one was to determine the average walking speed of pedestrian by considering the factors of age, gender, people with and without carrying baggage; and the second one was to make a comparison of the average walking speed that considered age as the factor of comparison between pedestrian at the bus terminal area and crosswalk. Demographic factor of pedestrian walking speed in this study are gender and age consist of male, female, and 7 groups of age categories that are children, adult men and women, senior adult men and women, over 70 and disabled person. Data of experiment was obtained by making a video recording of the movement of people that were walking and roaming around at the main lobby for 45 minutes by using a camcorder. Hence, data analysis was done by using software named Human Behaviour Simulator (HBS) for analysing the data extracted from the video. The result of this study was male pedestrian walked faster than female with the average of walking speed $1.13 \mathrm{~m} / \mathrm{s}$ and $1.07 \mathrm{~m} / \mathrm{s}$ respectively. Averagely, pedestrian that walked without carrying baggage had higher walking speed compared to pedestrian that were carrying baggage with the speed of $1.02 \mathrm{~m} / \mathrm{s}$ and $0.70 \mathrm{~m} / \mathrm{s}$ respectively. Male pedestrian walks faster than female because they have higher level of stamina and they are mostly taller than female pedestrian. Furthermore, pedestrian with baggage walks slower because baggage will cause distractions such as pedestrian will have more weight to carry and people tend to walk slower.
\end{abstract}

\section{Introduction}

Every person has their own preferred walking behaviour and the average walking speed of each person is different based on several factors such as age, gender, residential or working

\footnotetext{
* Corresponding author: sallehb@uthm.edu.my
} 
area, health etc. $[1-4,11]$. These factors can give impacts on the evacuation process during natural disaster or emergency situations in either confined or unconfined area. Other than that, pedestrian crossing time will also be influenced by the aforementioned factors that the timing for signalized crossing does not enough for certain pedestrian. Different people have different rate of walking speed and each person tend to walk at a speed that they find most comfortable for themselves and according to [5] the average walking speed of Malaysian was $1.16 \mathrm{~m} / \mathrm{s}$ at crosswalk. A study on the average walking speed can also be implemented at the bus terminal area to obtain the more accurate value of the walking speed of pedestrian. The difference that will be obtained in comparison with the previous study that was done by [5] can be useful for the improvement in traffic system, road design for pedestrian at signalized crossing and for the safety of building design for evacuation process during emergency situations.

In Malaysia, accidents are the third highest cause of death after heart and cancer diseases [6]. According to [7], it was reported that Malaysian pedestrian died due to traffic accidents were at the third rank in which the total of Malaysian pedestrian that were killed in 10 years from 2007 to 2016 was 5,472 and in 2016 alone was 511 as reported by [7]. The fatalities of pedestrian are usually caused by hit-and-run accidents, jaywalking, crossing busy roads and dangerous way of driving by road users and rank of pedestrian fatalities are at third rank after motorist and motorcyclist. Numbers of pedestrian accidents are rising due to the increasing number of vehicles and drivers yearly.

Pedestrian have different value of walking speed while walking at different locations as they walk based on the purpose and the environment of the walkway. Walking behaviour can be measured by using several parameters such as walking direction, walking speed, walking experience and other parameters that are considerable to be used [4]. In addition, there are several factors that influence the pedestrian walking behaviour and can be put into consideration in this field of research studies and they are pedestrian speed-density relationship, speed-flow relationship, pedestrian space requirement, pedestrian walking speed and pedestrian start-up time and capacity. Some people preferred to walk faster than others in situations like catching a public transport, rushing to work and those who do not like wasting time by walking slowly. Hence, it is beneficial to study about the walking behaviour to measure the walkability level in bus terminal area.

This research focuses on pedestrian at bus terminal that considers the pedestrian or the traveller that are using the terminal for transits or pedestrian who uses public transport. The data were analysed based on factors of gender, age, with and without carrying baggage. Therefore, this study aims to obtain the average walking speed of pedestrian with baggage, without baggage and the difference between average walking speed at terminal and at crosswalk. Density of vehicles on highway are categorized by the measurement of traffic flow and the traffic level based on speed of vehicles, density, type of vehicles, number of lanes, traffic phase etc. was used by traffic quality services are measured using qualitative measure using Level of Service (LOS). LOS for pedestrian facilities, the effectiveness is measured by pedestrian per unit area and the methods used to analyze is using Highway Capacity Manual (HCM). Based on T. V. Mathew (2014) [8], LOS of pedestrian consist of LOS A (Pedestrian Space $\left.>5.57 \mathrm{~m}^{2} / \mathrm{p}\right)$, LOS B (Pedestrian Space $\left.>3.716-5.574 \mathrm{~m}^{2} / \mathrm{p}\right)$, LOS C (Pedestrian Space $\left.>2.230-3.716 \mathrm{~m}^{2} / \mathrm{p}\right)$, LOS D (Pedestrian Space $>1.394-2.230 \mathrm{~m}^{2} / \mathrm{p}$ ), LOS E $\left(\right.$ Pedestrian Space $\left.>0.734-1.394 \mathrm{~m}^{2} / \mathrm{p}\right)$ and LOS F $\left(\right.$ Pedestrian Space $\left.=0.734 \mathrm{~m}^{2} / \mathrm{p}\right)$.

\section{Methodology}

During the experiment, a camcorder was used as the equipment for collecting the data of pedestrian and for the analysis part; it was done by using Human Behaviour Simulator (HBS) software that was plugged into Autodesk Maya software. The observation was 
conducted at the selected walkway that has high number of pedestrian. The age categories were categorized into 7 groups that are children $(<9$ years), adult men (10 39 years), adult women (10 39 years), senior adult men (40 69 years), senior adult women (40 69 years), over 70 years and disabled person. The pedestrian movement were recorded while walking at the pedestrian walkway or pedestrian crossing area and the video had been analysed by using Autodesk Maya and Human Behaviour Simulator (HBS) software to get the walking speed of each randomly selected person. The age groups were defined based on pedestrian attire and physical size that were done by visual judgment of author in analysing the data collected from video tape camera. Figure 1 shows image of female adult pedestrian tracking and the data of pedestrian coordinates was obtained from HBS tools.

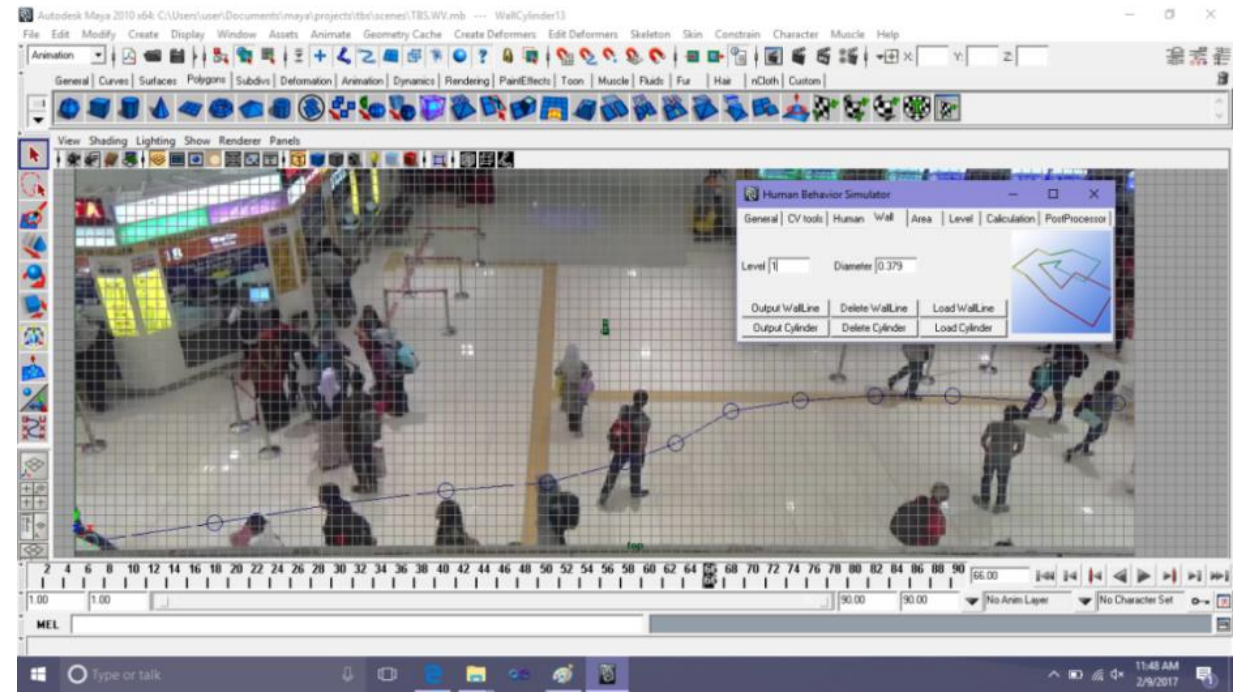

Fig. 1. Example of pointing out the coordinates of pedestrian movements.

There are 7 groups of pedestrians which are child, male adult, female adult, male senior adult, female senior adult, over 70 and disabled person and the descriptions for each category are shown in Table 1.

Table 1. Age categories' descriptions.

\begin{tabular}{|l|l|}
\hline \multicolumn{1}{|c|}{ Category } & \multicolumn{1}{c|}{ Description of age classification } \\
\hline Children & $\begin{array}{l}\text { Smaller body size (height), childish attire, normally } \\
\text { walking with family members. }\end{array}$ \\
\hline Adult (Men and women) & $\begin{array}{l}\text { Can be seen from the physical appearance, attire } \\
\text { and body movement that normally walk faster than } \\
\text { "Over 70" category. }\end{array}$ \\
\hline Senior adult (Men and women) & $\begin{array}{l}\text { Physical appearance, mostly walk slower than } \\
\text { "Senior adult" category and some walk by using } \\
\text { sticks. }\end{array}$ \\
\hline Over 70 (Men and women) & $\begin{array}{l}\text { Can be seen from their unusual gait and their } \\
\text { appearance. }\end{array}$ \\
\hline Disabled person
\end{tabular}

Data of experiments were analysed by using Human Behaviour Simulation (HBS) that was plugged into Autodesk Maya software. The video was converted from (avi.) format to (jpeg.) format by using Adobe after Effects CS4 software. The image sequences were imported to Autodesk Maya software and were analysed by every 1 second of video 
duration and the calculation of the data obtained from Autodesk Maya of walking speed among the selected pedestrian was done by using Microsoft Excel. Hence, the data had been classified in groups by categories of gender, age, person carrying baggage and person without carrying baggage.

\section{Results and discussions}

The results of this study are presented in Table 2 until Table 7.

Table 2. Pedestrian: average walking speed without carrying baggage.

\begin{tabular}{|l|c|c|c|c|c|}
\hline \multirow{2}{*}{ Category } & Number & \multirow{2}{*}{$\begin{array}{c}\text { Average } \\
\text { of data }\end{array}$} & \multirow{2}{*}{$\begin{array}{c}\text { Standard } \\
\text { deviation }(\mathbf{m} / \mathbf{s})\end{array}$} & \multicolumn{2}{c|}{ Range } \\
\cline { 5 - 6 } & 2 & 0.63 & 0.17 & 0.75 & 0.51 \\
\hline Child (below 9) & 186 & 1.20 & 0.07 & 1.94 & 1.10 \\
\hline Male adult (10-39) & 146 & 1.16 & 0.10 & 1.90 & 0.91 \\
\hline Female Adult (10-39) & 48 & 1.16 & 0.11 & 1.80 & 0.93 \\
\hline Male senior adult (40-69) & 19 & 1.07 & 0.20 & 1.17 & 0.82 \\
\hline Female senior adult (40-69) & 0 & 0 & - & - & - \\
\hline Over 70 & 1 & 0.87 & - & - & - \\
\hline Disabled person & - & 1.02 & 0.13 & - & - \\
\hline Average & 402 & - & - & - & - \\
\hline Total & & & & & \\
\hline
\end{tabular}

The average walking speed of the observed pedestrian without carrying baggage was $1.02 \mathrm{~m} / \mathrm{s}$. Table 2 shows that male adult pedestrian group walked faster than others. The speed of this group was also the highest as this group covers teenage and matured pedestrian that age from 10 to 39 years old with walking speed of $1.20 \mathrm{~m} / \mathrm{s}$. Secondly, it is logical as walking speed of pedestrian tends to decline as the pedestrian becomes older. The average of the lowest range of speed was $0.63 \mathrm{~m} / \mathrm{s}$ as obtained from child category.

Table 3. Pedestrian average walking speed with baggage.

\begin{tabular}{|c|c|c|c|c|c|}
\hline \multirow{2}{*}{ Category } & \multirow{2}{*}{$\begin{array}{c}\text { Number } \\
\text { of data }\end{array}$} & \multirow{2}{*}{$\begin{array}{c}\text { Average } \\
(\mathrm{m} / \mathrm{s})\end{array}$} & \multirow{2}{*}{$\begin{array}{c}\text { Standard } \\
\text { deviation }(\mathrm{m} / \mathrm{s})\end{array}$} & \multicolumn{2}{|c|}{ Range } \\
\hline & & & & High & Low \\
\hline Child (below 9) & 0 & - & - & - & - \\
\hline Male adult (10-39) & 21 & 1.15 & 0.04 & 1.20 & 1.06 \\
\hline Female Adult (10-39) & 43 & 1.05 & 0.07 & 1.12 & 0.86 \\
\hline Male senior adult (40-69) & 13 & 1.00 & 0.10 & 1.09 & 0.83 \\
\hline Female senior adult (40-69) & 8 & 0.98 & 0.10 & 1.09 & 0.83 \\
\hline Over 70 & 0 & 0 & - & - & - \\
\hline Disabled person & 0 & 0 & - & - & - \\
\hline Average & - & 0.70 & 0.31 & - & - \\
\hline Total & 85 & - & - & - & - \\
\hline
\end{tabular}

Average walking speed of pedestrian carrying baggage from the observations at bus terminal area was $0.70 \mathrm{~m} / \mathrm{s}$. Table 3 shows female adult pedestrian walked slower than male adult pedestrians which are $1.15 \mathrm{~m} / \mathrm{s}$ and $1.05 \mathrm{~m} / \mathrm{s}$ respectively and same goes to the comparison between male and female senior adult in which the walking speed rate of male senior adult is slightly higher than senior female adult pedestrians with the speed of 1.00 $\mathrm{m} / \mathrm{s}$ and $0.98 \mathrm{~m} / \mathrm{s}$ respectively. That shows both male pedestrian groups walked faster than female pedestrian groups. Therefore, the highest walking speed of this group was male adult pedestrian with $1.15 \mathrm{~m} / \mathrm{s}$. 
Table 4. Average walking speed of pedestrian with and without carrying baggage correspond to age.

\begin{tabular}{|l|c|c|c|}
\hline \multirow{2}{*}{ Category } & \multirow{2}{*}{$\begin{array}{c}\text { Percentage } \\
\text { (\%) }\end{array}$} & \multicolumn{2}{c|}{ Average walking speed (m/s) } \\
\cline { 3 - 4 } & & With baggage & Without baggage \\
\hline Child (below 9) & - & 0 & 0.63 \\
\hline Male adult (10-39) & 4 & 1.15 & 1.20 \\
\hline Female Adult (10-39) & 9 & 1.05 & 1.16 \\
\hline Male senior adult (40-69) & 13 & 1.00 & 1.16 \\
\hline Female senior adult (40-69) & 8 & 0.98 & 0 \\
\hline Over 70 & - & 0 & 0.87 \\
\hline Disabled person & - & 0 & - \\
\hline Total & 34 & - & \\
\hline
\end{tabular}

Table 4 shows the reduction of average walking speed when pedestrian carrying baggage while walking at bus terminal. The result shows that carrying baggage was one of the reduction factors on walking speed of pedestrian because of the size and weight of baggage. Male senior adult category had the highest reduction walking speed with $13 \%$ off than walking speed of pedestrian without baggage. It's followed by female adult pedestrian and female senior adult with $9 \%$ and $8 \%$ drop respectively. Male adult pedestrian category had the lowest reduction on walking speed, with only $4 \%$ drop and male adult still walked faster compared to other age groups. Therefore, pedestrian that walk while carrying baggage have slower walking speed as they need to carry more weight that will distract them to walk faster. This can be supported by [12] that have observed pedestrian who walk with baggage tend to walk slower than non-carrying baggage that corresponds to the size and weight of baggage. Consequently, the total reduction of the average walking speed between pedestrian carrying baggage and without carrying baggage was $34 \%$.

Table 5. Pedestrian walking speed correspond to gender.

\begin{tabular}{|l|c|c|c|c|c|}
\hline \multirow{2}{*}{ Gender } & Number of & Average & \multirow{2}{*}{$\begin{array}{c}\text { Standard } \\
\text { data }\end{array}$} & $(\mathbf{m} / \mathbf{s})$ & \multicolumn{2}{c|}{ Range } \\
\cline { 5 - 6 } & deviation $(\mathbf{m} / \mathbf{s})$ & High & Low \\
\hline Child & 2 & 0.63 & 0.17 & 0.75 & 0.51 \\
\hline Male & 234 & 1.13 & 0.08 & 1.00 & 0.08 \\
\hline Female & 165 & 1.07 & 0.12 & 0.64 & 0.14 \\
\hline Over 70 & 0 & 0 & - & - & - \\
\hline Disabled person & 1 & 0.87 & - & - & - \\
\hline Average & - & 0.93 & 0.12 & - & - \\
\hline Total & 402 & - & - & - & - \\
\hline
\end{tabular}

Table 5 shows that male pedestrian was found to walk faster than female pedestrian with the speed of $1.13 \mathrm{~m} / \mathrm{s}$ and $1.03 \mathrm{~m} / \mathrm{s}$ respectively. These findings support the results of previous studies $[2,9]$. According to [10], female pedestrian walked slower with the speed of $1.07 \mathrm{~m} / \mathrm{s}$ compared to male that walked with the speed of $1.24 \mathrm{~m} / \mathrm{s}$. Female pedestrian specifically in Malaysia tend to walk slower compared to male pedestrian because of their attire in which some of them are wearing Baju Kurung which is one of the Malaysian female traditional attires, skirts and high heels also can cause them to walk slower. These findings also supported by the results from previous study of [10] that found female pedestrians walked slower than male pedestrian by nearly $0.17 \mathrm{~m} / \mathrm{s}$ of difference. 
Table 6. Average walking speed of Malaysian pedestrian at crosswalk [5].

\begin{tabular}{|l|c|c|c|}
\hline \multicolumn{1}{|c|}{ Category } & $\begin{array}{c}\text { Number } \\
\text { of data }\end{array}$ & $\begin{array}{c}\text { Average walking } \\
\text { speed (m/s) }\end{array}$ & $\begin{array}{c}\text { Standard } \\
\text { deviation (m/s) }\end{array}$ \\
\hline Child (below 9) & 90 & 1.06 & 0.15 \\
\hline Male adult (10-39) & 337 & 1.35 & 0.16 \\
\hline Female Adult (10-39) & 351 & 1.20 & 0.15 \\
\hline Male senior adult (40-69) & 175 & 1.14 & 0.15 \\
\hline Female senior adult (40-69) & 139 & 1.04 & 0.13 \\
\hline Average & - & 1.16 & 0.15 \\
\hline Total & 1,092 & - & - \\
\hline
\end{tabular}

Table 7. Average walking speed of Malaysian pedestrian at bus terminal area.

\begin{tabular}{|l|c|c|c|}
\hline \multicolumn{1}{|c|}{ Category } & $\begin{array}{c}\text { Number } \\
\text { of data }\end{array}$ & $\begin{array}{c}\text { Average walking } \\
\text { speed (m/s) }\end{array}$ & $\begin{array}{c}\text { Standard } \\
\text { deviation (m/s) }\end{array}$ \\
\hline Child (below 9) & 2 & 0.63 & 0.17 \\
\hline Male adult (10-39) & 186 & 1.20 & 0.07 \\
\hline Female Adult (10-39) & 146 & 1.16 & 0.10 \\
\hline Male senior adult (40-69) & 48 & 1.16 & 0.11 \\
\hline Female senior adult (40-69) & 19 & 1.07 & 0.20 \\
\hline Average & - & 1.04 & 0.13 \\
\hline Total & 401 & - & - \\
\hline
\end{tabular}

The average walking speeds of pedestrian are varying at different locations because of the surroundings, environment, walking space etc. For this study, the comparison was made between the average walking speed at bus terminal and pedestrian crosswalk. The previous study that had been conducted by [5] was to determine the average walking speed of pedestrian at crosswalk area and the result is shown in Table 6. Table 7 shows the results of the average walking speed of pedestrian at bus terminal area as conducted for this research. The results of the average walking speed of both locations have differences in which some pedestrian at crosswalk walked faster if compared to those at bus terminal. The highest difference of percentage on average walking speed at crosswalk and terminal area was child with $40 \%$ reduction percentage. The difference of percentage is higher because the number of sample of child at bus terminal as observed was lower than crosswalk area. Besides, both male and female adult pedestrian at crosswalk had higher walking speed than male and female adult pedestrian at bus terminal with $11 \%$ and $3 \%$ differences respectively. On the contrary, male senior adult and female senior adult at bus terminal had higher walking speed compared to male senior adult and female senior adult pedestrian at crosswalk with $2 \%$ and $3 \%$ differences respectively.

\section{Conclusions}

From the data analysis, there were slight differences in walking speed of the aforementioned factors. Pedestrian without baggage had the walking speed of $1.02 \mathrm{~m} / \mathrm{s}$ while the walking speed of pedestrian with baggage was $0.70 \mathrm{~m} / \mathrm{s}$. Moreover, the average walking speed of pedestrian by gender both male and female were $1.13 \mathrm{~m} / \mathrm{s}$ and $1.07 \mathrm{~m} / \mathrm{s}$ respectively. The obtained results have proven that pedestrian with baggage tend to walk slower than pedestrian without baggage and male pedestrian walked faster than female pedestrian. The data from "Child", "Over 70", and "Disabled Persons" were not being able to be obtained precisely because most of the pedestrian at the location were not among those three categories. In comparison, pedestrian at crosswalk walked faster than pedestrian at the bus terminal area due to some factors that give influence to the decision of every 
pedestrian to either walk faster or slower such as, this situation will happen when the LOS of pedestrian increases in which the higher density of pedestrian at the bus terminal will cause the pedestrian to walk slower as the walkway or their personal space of walking are smaller. Other than that, time constrain can be considered as a factor that affect the walking speed of pedestrian at crosswalk to be higher than the walking speed at bus terminal. For example, some pedestrian at crosswalk tend to walk faster when catching the regular public buses at one stop to another and it is different than the situation of the buses at bus terminal area that are time-based centralized that helps people in estimating their time for the departure. Additionally, people tend to walk faster at crosswalk because of the hot or rainy weather and due to time limitation given for crossing the road. Therefore, this study can be useful as a reference for understanding the walking speed of Malaysian specifically at the bus terminal area and this field of research can be expanded in understanding the Malaysian walking speed in more locations of the pedestrian walking facilities for future improvements.

This research is funded by the Ministry of Higher Education (MOHE) of Malaysia under Fundamental Research Grant Scheme (FRGS) (Vot 1526).

\section{References}

1. T.J. Gates, D.A Noyce, A.R. Bill, N. Van Ee, T.J. Gates, Proceeding of TRB 2006 Annual Meeting (2006)

2. K.K. Finnis, D. Walton, $2^{\text {nd }}$ International conference on sustainability engineering and science

3. R. Rastogi, S. Chandra, European Transport (Trasporti Europei (EUT Edizioni Università di Trieste di Trieste, 2013)

"Pedestrian Flow Characteristics for Different Facilities and Situations," (2013)

4. D. I. Azmi, H. A. Karim, M. Z. M. Amin, Journal of Asian Behavioral Studies, 11, $97-$ 110 (2013)

5. M.S. Abustan, E. Harada, H. Gotoh, Proceeding of Coastal Engineering, JSCE, 3, 56$60(2012)$

6. B. H. Goh, K. Subramaniam, Y. T. Wai, A. A. Mohamed, A. Ali, International Journal for Traffic and Transport Engineering 2, 323-332 (2012)

7. JKJR. (2016). Jabatan Keselamatan Jalan Raya Malaysia. Retrieved from http://www.jkjr.gov.my/ms/maklumat_keselamatan/statistik/func-startdown/125/

8. T. V. Mathew, Indian Institute of Technology Bombay (2014)

9. B. P Devkota, Proceeding of IOE Graduate Conference, 185 (2014)

10. K. Rahman, N. A. Ghani, A. A. Kamil, A. Mustafa, Research journal of applied sciences, engineering and technology 4, 4299-4304 (2012)

11. F. Ghani, J.N., Rachele, S., Washington, G., Turrell, Prev Med Rep. 4, 75-80 (2016)

12. K.K, Laxman, R. Rastogi, S., Chandra, Journal of Urban Planning and Development, 136, 23-33 (2010) 